\title{
Temperature-dependent growth rate and photosynthetic performance of Antarctic symbiotic alga Trebouxia sp. cultivated in a bioreactor
}

\author{
Kateřina Balarinová ${ }^{1}$, Peter Váczi ${ }^{1}$, Miloš Barták $^{1 *}$, Jana Hazdrová ${ }^{1}$, \\ Marie Forbelská ${ }^{2}$ \\ ${ }^{I}$ Department of Experimental Biology, Laboratory of Photosynthetic Processes, Faculty \\ of Science, Masaryk University, University Campus - Bohunice, Kamenice 5, 62500 \\ Brno, Czech Republic \\ ${ }^{2}$ Department of Mathematics and Statistics, Faculty of Science, Masaryk University, \\ Kotlářská 2, 61137 Brno, Czech Republic
}

\begin{abstract}
Optimum growth temperature of Trebouxia sp. (re-classified as Asterochloris sp. recently), a symbiotic lichenized alga was evaluated using a batch culture cultivated in a bioreactor. The algae were isolated from lichen thalli of Usnea antarctica collected at the James Ross Island, Antarctica in February 2012. The algae were isolated under laboratory conditions and then cultivated on agar medium at $5^{\circ} \mathrm{C}$. When sufficiently developed, the algae were suspended in a BBM liquid medium and cultivated in a photobioreactor for 33 days at either 15 , or $10^{\circ} \mathrm{C}$. During cultivation, optical density (OD) characterizing culture growth, and effective quantum yield of photosystem II $\left(\Phi_{\text {PSII }}\right)$ characterizing photosynthetic performance were measured simultaneously. Thanks to higher $\Phi_{\text {PSII }}$ values, faster growth was achieved at $10^{\circ} \mathrm{C}$ than $15^{\circ} \mathrm{C}$ indicating that Trebouxia sp. might be ranked among psychrotolerant species. Such conclusion is supported also by a higher specific growth rate found during exponential phase of culture growth. The results are discussed and compared to available data on temperaturedependent growth of polar microalgae.
\end{abstract}

Key words: Usnea antarctica, chlorophyll fluorescence, lichen, effective quantum yield, James Ross Island, psychrotolerance, Asterochloris

Abbreviations: $\Phi_{\mathrm{PSII}}$ - effective quantum yield of photosystem II, $\mu$ - specific growth rate, OD - optical density, PBRr - photobioreactors

DOI: $10.5817 / C P R 2013-1-4$

Received January 5, 2013, accepted March 31, 2013.

*Corresponding author: Miloš Barták <mbartak@sci.muni.cz>

Acknowledgement: The authors thank the project CzechPolar for providing the infrastructure of the

Johann Gregor Mendel station during sample collection in February 2012 as well as the EEL laboratory for the support provided during the cultivation of Trebouxia sp. 


\section{Introduction}

Trebouxia sp. is a green unicellular microalga. It belongs to division Chlorophyta, class Trebouxiophyceae, order Trebouxiales. Recently, it is re-classified as Asterochloris (Peksa et Škaloud 2011). Although there are various types of photobionts in the lichens, algae of genus Trebouxia sp. are well known as a photobionts presented in two thirds of all lichen species. It is found also in extremophillic lichens growing in Antarctica, including Usnea antarctica, U. sphacelata and $U$. aurantiaco-atra, most common fruticose species found at the islands on the west (South Shetlands, Argentine Islands) and east side of the Antarctic Peninsula (James Ross Island group). Trebouxia sp. is a typical photobiont for the lichens of genus Usnea, however, Poterioochromonas sp. is recently reported as rare co-occurring symbiont in Usnea longissima (He et Zhang 2012). In general, cells of Trebouxia sp. has about $10-15 \mu \mathrm{m}$ in diameter. There is about 26 species in this genus.

Trebouxia sp. reproduces asexually by autospores or zoospores. Sexually reproductive stages have not been observed directly in any genus of class Trebouxiophyceae (Lewis et McCourt 2004). Species of genus Trebouxia differ in morphology of plastids and structure of pyrenoids (Friedl 1989). Many species of genus Trebouxia has been studied, but there is still little known about its physiological characteristics and photosyntetic parameters. However, there is a basic knowledge about its photosynthetic responses to heavy metal induced stress (e.g. Branquinho et al. 2011, Piovar et al. 2011), high light stress (Showman 1972), dehydration stress (Wieners et al. 2012), osmotic (Váczi et Barták 2006) and oxidative-induced stress (Del Hoyo et al. 2011). The alga is in many cases studied as a part of lichen thalli (e.g. Alvarez et al. 2012, Branquino et al. 2011).
Trebouxia sp. algae are considered either psychrophilic or psychrotolerant. Psychrophilic algae grow at temperatures below $0{ }^{\circ} \mathrm{C}$ and typically have temperature growth maxima only a few degrees above zero. Typical psychrophilic algae, such as e.g. genera Chlamydomonas and Chloromonas are found in polar regions. They have growth optimum below $10^{\circ} \mathrm{C}$. In spite of the fact that lichenized Trebouxia thrives well in cold polar environments, its growth optimum is reported above $15^{\circ} \mathrm{C}$ (Kvíderová et al. 2010). Therefore, it may be ranked rather psychrotolerant than psychrophilic.

For long-term storage, symbiotic algae are mostly cultivated on agar plates in Petri dishes. Cultivation on agar plates is also used to develop cultures suitable for determination purposes (Gärtner et Inolić 1998). Cultures on agars and/or nitrocellulose disks are frequently used in the experiments studying stress-induced physiological responses, such as e.g Trebouxia sensitivity to heavy metals (Piovar et al. 2011), photosynthesis sensitivity to low temperature and drought stress (Sadowsky et Ott 2012). Another possibility is to cultivate the alga in a liquid medium. For cultivation of lichen symbiotic algae, a variety of liquid media and volumes of cell culture flasks is used. This approach was applied in the experiments studying dehydration (Wieners et al. 2012, Gasulla et al. 2013), and oxidative stress effects (Del Hoyo et al. 2011). Recently, photobioreactors (PBRs) are used in cultivation of numerous algal species. There are many types of photobioreactors - e.g. large open ponds, enclosed flat-plate PBRs, vertical column PBRs, panel PBRs and smaller indoor PBRs. Algae cultivated in large outdoor photobioreactors can be used for the production of some bioactive substances (Fu et al. 2012). Small indoor bioreactors are often used for laboratory experiments or growth analysis of algal 
cultures using different indicators, such as e.g. changes in various physiological parameters caused by cultivation temperature and/or photosynthetic radiation. There are some advantages of using these bioreactors for algae cultivation such as e.g. the possibility of automatic continual measurements of physiological parameters during the whole cultivation period. In our study, we used a PBR for long-term cultivation in liquid medium to evaluate temperature optimum.

\section{Material and Methods}

Trebouxia sp. was isolated from an Antarctic lichen Usnea antarctica collected at the James Ross Island (63.81 S, $57.83 \mathrm{~W})$. The isolation was done by a gradient centrifugation method according to Gasulla et al. (2010) using a Percoll®. After isolation, the alga was cultivated on agar medium at $5^{\circ} \mathrm{C}$. When algal culture was sufficiently developed, it was collected from the surface of agar medium and suspended in a liquid medium (nitrogen-enriched anorganic Bold's Basal Medium, 3N-BBM, Ahmadjian 1993). Then, it was cultivated in a FMT-150/400 photobioreactor (PSI, Czech Republic) for 33 days. For cultivation, two different growth temperatures $\left(15^{\circ} \mathrm{C}, 10^{\circ} \mathrm{C}\right)$ and $16 / 8 \mathrm{~h}$ light/dark period were used (70 $\left.\mu \mathrm{mol} \mathrm{m} \mathrm{m}^{-2} \mathrm{~s}^{-1}\right)$. The photobioreactors had a flat - vessel design that enabled uniform illumination within the whole volume of cultivated culture of Trebouxia sp. During cultivation, optical density (OD at $680 \mathrm{~nm}$ ) of Trebouxia sp. culture, and effective quantum yield $\left(\Phi_{\mathrm{PSII}}\right)$ of photosynthetic processes in photosystem II were measured repeatedly. This was possible thanks to integrated densitometer that measured light scattering at $680 \mathrm{~nm}$ and a fluorometer that measured fluorometric signals Fm' and Fs from which $\Phi_{\text {PSII }}$ was calculated $\left(\Phi_{\text {PSII }}=[\right.$ Fm'- Fs $] /$ Fm', Genty et al. 1989). Finally, OD and $\Phi_{\text {PSII }}$ were plotted against the time of cultivation, so that temperature-induced differences in growth rate and photosynthetic efficiency could be distinguished. The relations of OD and $\Phi_{\text {PSII }}$ to the time of cultivation were fitted by S-curves using the below log-logistic model with five parameters:

$$
f(x)=C+\frac{D-C}{\left[1+\left(\frac{x}{E}\right)^{B}\right]^{F}}
$$

where $\mathrm{B}$ is Hill slope, $\mathrm{C}$ is minimum value, $\mathrm{D}$ is maximum value of dependent variable, $\mathrm{E}$ is $\mathrm{C}_{50}$, and $\mathrm{F}$ is parameter describing asymmetry of S-curve.

Since the values of OD were measured repeatedly throughout cultivation time, specific growth rate $(\mu)$ was calculated for $50 \mathrm{~h}$ subperiods using the below equation:

$\mu=\left(\mathrm{N}_{2}-\mathrm{N}_{1}\right) / \mathrm{t}_{2}-\mathrm{t}_{1}$

where $t_{2}, t_{1}$ are the times within the exponential phase of culture growth $\left(t_{2}>t_{1}, t_{2}-t_{1}=50\right.$ h). $N_{2}$ is optical density (OD) derived from the fitted $S$ curve at $t_{2}, N_{1}$ is OD at $t_{2}$. 


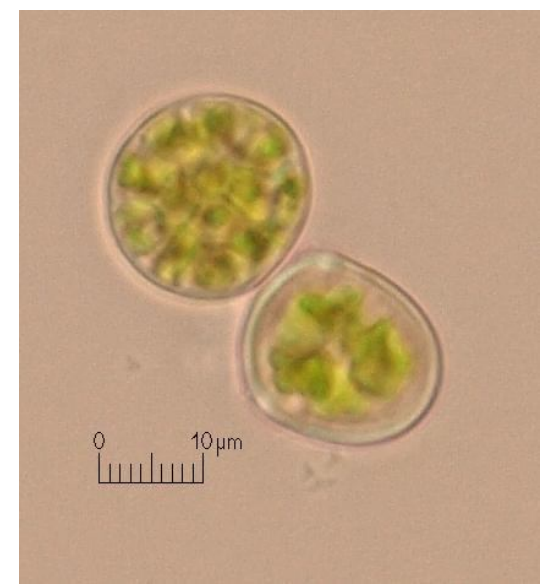

Fig. 1. Trebouxia sp. cells isolated from Usnea antarctica collected at the James Ross Island, Antarctics. (C) Photo: K. Trnková.

\begin{tabular}{|ccccc|}
\hline & Estimate & Std.Error & t-value & p-value \\
\hline b:1 & -0.43 & 0.13 & -3.30 & 0.00 \\
c: 1 & 0.13 & 0.01 & 19.60 & 0.00 \\
d:1 & 4.73 & 5.15 & 0.92 & 0.36 \\
e:1 & 554.45 & & & \\
f:1 & 4.91 & & & \\
b:2 & -46.91 & 24.74 & -1.90 & 0.06 \\
c:2 & 0.12 & 0.01 & 22.49 & 0.00 \\
d:2 & 0.41 & 0.00 & 105.44 & 0.00 \\
e:2 & 490.47 & 7.41 & 66.17 & 0.00 \\
f:2 & 0.06 & 0.03 & 1.83 & 0.07 \\
\hline
\end{tabular}

Table 1. Generalized log-logistic parameters of S-curve (see Eqn. 1) fitting data points of optical density (OD) of Trebouxia sp. culture as dependent on the time of cultivation.

\section{Results}

Time courses of OD showed that faster growth of Trebouxia sp. was achieved at $10^{\circ} \mathrm{C}$ than $15^{\circ} \mathrm{C}$. At $10^{\circ} \mathrm{C}$, the culture OD showed typical $\mathrm{S}$ curve, with maximum growth rate found after $420 \mathrm{~h}$ of cultivation. At $15^{\circ} \mathrm{C}$, however, the $\mathrm{OD}$ values exhibited rather constant growth rate (see Fig. 2, Table 3). Final culture density was

\begin{tabular}{|ccccc|}
\hline & Estimate & Std.Error & t-value & p-value \\
\hline b:1 & 15.85 & 16.45 & 0.96 & 0.34 \\
c: 1 & 0.55 & 0.01 & 88.03 & 0.00 \\
d:1 & 0.61 & 0.01 & 74.38 & 0.00 \\
e: 1 & 439.89 & 254.17 & 1.73 & 0.09 \\
f:1 & 21.87 & 168.99 & 0.13 & 0.90 \\
b:2 & -189.89 & 183.34 & -1.04 & 0.30 \\
c:2 & 0.68 & 0.01 & 97.31 & 0.00 \\
d:2 & 0.85 & 0.01 & 126.09 & 0.00 \\
e:2 & 429.84 & 4.31 & 99.69 & 0.00 \\
f:2 & 0.22 & 0.26 & 0.84 & 0.40 \\
\hline
\end{tabular}

Table 2. Generalized log-logistic parameters of S-curve (see Eqn. 1) fitting data points of effective quantum yield of PS II $\left(\Phi_{\mathrm{PSII}}\right)$ of Trebouxia sp. culture as dependent on the time of cultivation. higher when cultivated at $10^{\circ} \mathrm{C}(\mathrm{OD}=$ $0.45)$ than $15^{\circ} \mathrm{C}(\mathrm{OD}=0.35)$ indicating that optimum cultivation temperature for Trebouxia sp. is definitely below $15^{\circ} \mathrm{C}$. Such conclusion is supported also by fluorometric data. While effective quantum yield $\left(\Phi_{\mathrm{PSII}}\right)$ reached relatively lowered value ranging from 0.5 to 0.7 at 
$15^{\circ} \mathrm{C}$, it was much higher at $10^{\circ} \mathrm{C}(0.6$ $0.8)$. Moreover, $\Phi_{\mathrm{PSII}}$ showed increasing values with cultivation time indicating progressive acclimation to cultivation conditions $\left(10^{\circ} \mathrm{C}\right)$, highly effective performance of photosynthetic apparatus at such more favourable temperature. At $15^{\circ} \mathrm{C}$, contrastingly, $\Phi_{\mathrm{PSII}}$ exhibited slightly decreasing trend with cultivation time. This finding supports the conclusion that $15^{\circ} \mathrm{C}$ is suboptimal cultivation temperature for Trebouxia sp. cultured in liquid medium.

\begin{tabular}{|l|c|c|}
\hline \multirow{2}{*}{ Days of cultivation } & \multicolumn{2}{|c|}{ Cultivation temperature } \\
\hline Intervals (h) & $\mathbf{1 5}^{\circ} \mathbf{C}$ & $\mathbf{1 0}^{\circ} \mathbf{C}$ \\
\hline $0-50$ & $\boldsymbol{\mu}_{15}$ \\
\hline $50-100$ & 0.0001 & below 0.0001 \\
\hline $100-150$ & 0.0002 & below 0.0001 \\
\hline $150-200$ & 0.0003 & 0.0001 \\
\hline $200-250$ & 0.0003 & 0.0003 \\
\hline $250-300$ & 0.0003 & 0.0004 \\
\hline $300-350$ & 0.0003 & 0.0006 \\
\hline $350-400$ & 0.0003 & 0.0008 \\
\hline $400-450$ & 0.0003 & 0.0010 \\
\hline $450-500$ & 0.0003 & 0.0013 \\
\hline
\end{tabular}

Table 3. Specific growth rate $(\mu)$ derived from optical density (OD) measurements of Trebouxia sp. cultured in a photobioreactor at 10 and $15^{\circ} \mathrm{C}$.

\section{Discussion}

In this study, an optimum growth temperature of Trebouxia sp. cultivated in batch culture was studied using two cultivation temperatures $\left(10\right.$ and $\left.15^{\circ} \mathrm{C}\right)$. Faster growth found for Trebouxia sp. cultivated at $10^{\circ} \mathrm{C}$ is well comparable to the results of Teoh et al. (2004) who investigated growth of several Antarctic microalgae in response to temperature. The authors reported the highest specific growth rates for temperature ranging from $6^{\circ} \mathrm{C}$ to $14^{\circ} \mathrm{C}$. Similarly, earlier study of Seaburg et al. (1981) showed that optimum growth temperature for 35 species of Antarctic microalgae ranged between 7.7 to $18^{\circ} \mathrm{C}$. Fogliano et al. (2010) reported that Koliella antarctica, an unicellular extremophilic green alga from the Ross Sea, Antarctica, exhibited higher growth rates and biomass production in $15^{\circ} \mathrm{C}$ than in $10^{\circ} \mathrm{C}$ of cultivation temperature. This seems to be contradictory to our findings since in Trebouxia sp., there was faster growth and $\mathrm{OD}$ values found in $10^{\circ} \mathrm{C}$ than in $15^{\circ} \mathrm{C}$ (see Fig. 2). However, Fogliano et al. (2010) measured only the initial phase of growth (10 d), while our results showed completed S-curves reaching maximum constant value of OD because of long-term cultivation (more than one month). During the first 7 day of cultivation Trebouxia sp., similarly to $K$. antarctica exhibited higher 


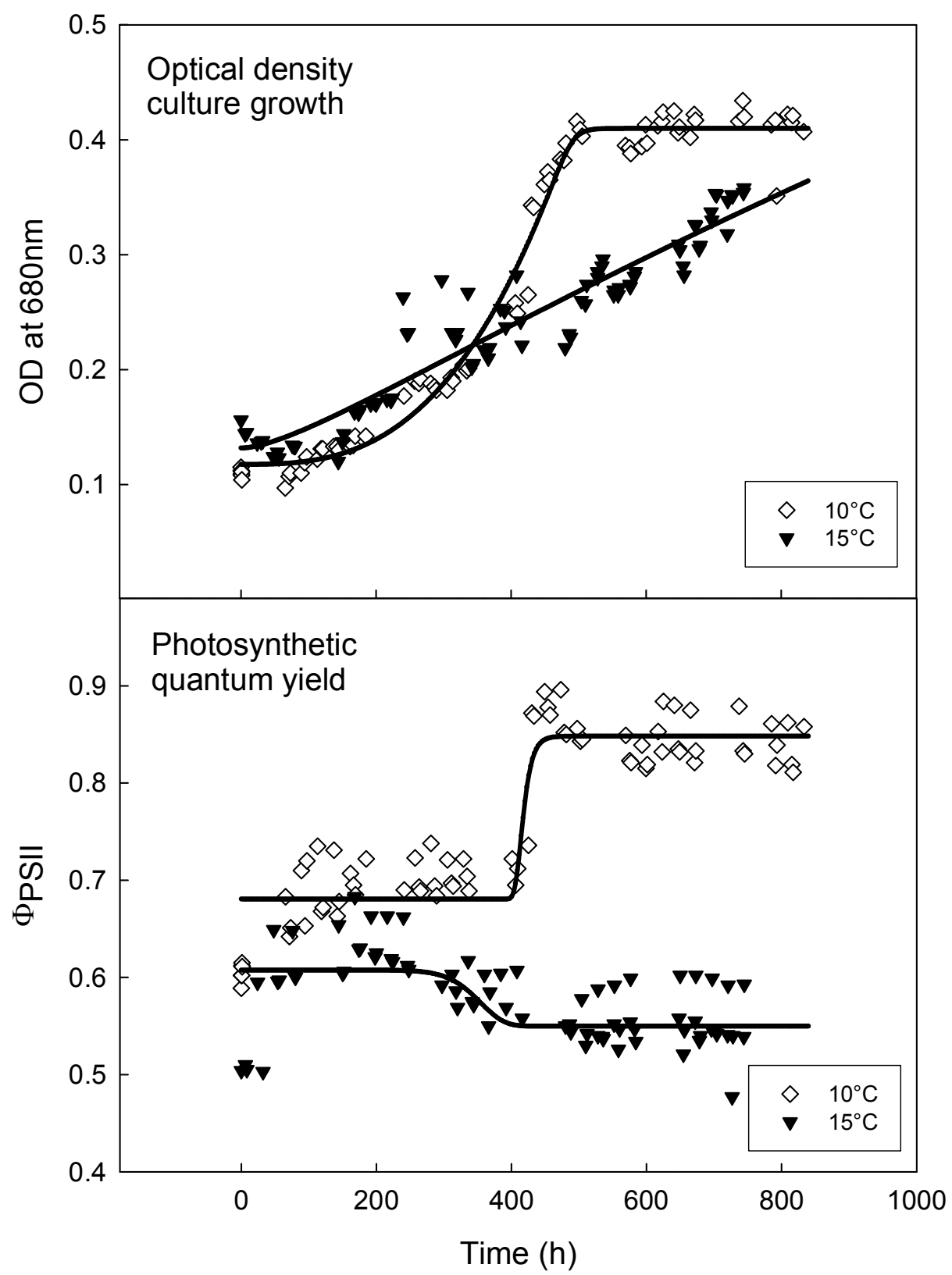

Fig. 2. Time courses of optical density (OD, the upper panel), and effective quantum yield of photosystem II ( $\Phi_{\mathrm{PSII}}$, the lower panel) in the culture Trebouxia sp. cultivated in a photobioreactor at two growth temperatures: $10^{\circ} \mathrm{C}$ (open symbols), and $15^{\circ} \mathrm{C}$ (full symbols). 
OD in $15^{\circ} \mathrm{C}$, while further cultivation led to more rapid growth in 10 then $15^{\circ} \mathrm{C}$. Some unicellular algae from Antarctica, however, exhibit higher growth rates in cultivation temperature above $20^{\circ} \mathrm{C}$, as reported by Chen et al. (2012) for Stichococcus (Trebouxiophyceae) and Blanc et al. (2012) for polar alga Coccomyxa subellipsoidea.

In our experiment, Trebouxia sp. exhibited higher values of $\Phi_{\text {PSII }}$ and resulting biomass at the temperature of $10^{\circ} \mathrm{C}$ throughout the cultivation. Therefore, the Trebouxia strain isolated from lichen thalli of Usnea antarctica could be ranked among psychrophilic algae because similar responses, i.e. optimum growth at temperature below $15^{\circ} \mathrm{C}$ is reported by Vona et al. (2004) for cryophilic alga Koliella antarctica. Such conclusion may be supported also by the study of OcampoFriedmann et al. (1988) who classified two species of genus Trebouxia from Antartica as psychrophilic algae with temperature optimum around $17.5^{\circ} \mathrm{C}$. The algae of genus Trebouxia, however, are present in many lichen species distributed worldwide. Across vegetation zones, chlorolichens that have Trebouxia sp. as photosynthetic partner occupy a wide range of ecosystems with the temperature regimen differing from polar region habitats. Therefore, the genus Trebouxia should be

\section{Concluding remarks}

In this study, we support the idea that Trebouxia sp. isolated from Antarctic lichen Usnea antarctica could be ranked among psychrotolerant species. Recent knowledge on temperature dependence of particular photo- and biochemical processes of photosynthesis in Trebouxia from polar regions is, however, still inadequate. Therefore, axenic cultures of Trebouxia $\mathrm{sp}$. grown in liquid medium represent an classified rather psychrotolerant than psychrophilic.

Simultaneous measurements of optical density (OD) and $\Phi_{\text {PSII }}$ during the cultivation of the culture allowed to analyze their relationship. When cultivated at $10^{\circ} \mathrm{C}$, Trebouxia showed absolute maximum of growth rate at the same time, at which an increase in $\Phi_{\text {PSII }}$ values was recorded (see Fig. 2, Table 3, 400-420 h of cultivation). Such increase in the effectivity of photosynthetic processes in photosystem II is thus responsible for an acceleration of Trebouxia culture growth. This conclusion can be supported by the two facts: (1) No such increase in $\Phi_{\text {PSII }}$ was found at higher cultivation temperature $\left(15^{\circ} \mathrm{C}\right)$ simultaneously with no change in OD, (2) whenever $\Phi_{\text {PSII }}$ of Trebouxia cultured at $10^{\circ} \mathrm{C}$ reached constant value after the previous increase (see Fig. 2, 480 h), OD became constant indicating that the culture reached maximum density. Generally, the time required for reaching final density of Trebouxia culture was much longer $(840 \mathrm{~h})$ than reported for majority of temperate unicellular freshwater (e.g. Chlamydomonas reinhardtii in Morlon et al. $2005-120 \mathrm{~h}$ ) and marine alga (e.g. Chlorella minutissima in Sankar et al. $2011-350 \mathrm{~h}$ ).

excellent tool to study Trebouxia resistance to low temperature and freezing stress (Hájek et al. 2012). Our further study (Barták et al., MS in prep.) will be focused on inhibition of photochemical processes in photosystem II in isolated Trebouxia sp. in relation to gradual cooling of the culture from physiological to freezing temperature. 
K. BALARINOVÁ et al.

\section{References}

Ahmadjian, V. (1993): The Lichen Symbiosis. John Wiley \& Sons, New York. 250 p.

Alvarez, R., Del Hoyo, A., Garcia-Breijo, F., Reig-Armiñana, J., Del Campo, E. M., Guéra, A., BARREno, E. and CASANO, L. M. (2012): Different strategies to achieve Pb-tolerance by the two Trebouxia algae coexisting in the lichen Ramalina farinacea. Journal of Plant Physiology, 169: 1797-1806.

Blanc, G., Agarkova, I., Grimwood, J., Kuo, A., Brueggeman, A., Dunigan, D. D., Gurnon, J., Ladunga, I., Lindquist, E., Lucas, S., Pangilinan, J., Pröschold, T., Salamov, A., Schmutz, J., Weeks, D., Yamada, T., Lomsadze, A., Borodovsky, M., Claverie, J.-M., GrigorieV, I.V. and VAN EtTEN, J. L. (2012): The genome of the polar eukaryotic microalga Coccomyxa subellipsoidea reveals traits of cold adaptation. Genome Biology, 13 (R39): 1-12.

Branquinho, C., Matos, P., Vieira, A. R. and Prestello-Ramos, M. M. (2011): The relative impact of lichen symbiotic partners to repeated copper uptake. Environmental and Experimental Botany, 72: 84-92.

CHEN, Z., He, CH. and Hu, H. (2012): Temperature responses of growth, photosynthesis, fatty acid and nitrate reductase in Antarctic and temperate Stichococcus. Extremophiles, 16: 127-133.

Del Hoyo, A., Álvarez, R., Del Campo, E. M., Gasulla, F., Barreno, E. and Casano, L. M. (2011): Oxidative stress induces distinct physiological responses in the two Trebouxia phycobionts of the lichen Ramalina farinacea. Annals of Botany, 107: 109-118.

Fogliano, V., Andreoli, C., Martello, A., Caiazzo, M., Lobosco, O., Formisano, F., Carlino, P. A., Meca, G., Graziani, G., Di Martino Rigano, V., Vona, V., Carfagna, S. and Rigano, C. (2010): Functional ingredients produced by culture of Koliella antarctica. Aquaculture, 299: $115-120$.

FrIEDL, T. (1989): Comparative ultrastructure of pyrenoids in Trebouxia (Microthamniales, Chlorophyta). Plant Systematics and Evolution, 164: 145-159.

Fu, W., Gudmundsson, O., Feist, A. M., Herjolfsson, G., Brynjolfsson, S. and Palsson, B. Ø. (2012): Maximizing biomass productivity and cell density of Chlorella vulgaris by using lightemitting diode-based photobioreactor. Journal of Biotechnology, 161: 242-249.

GÄRTNER, G., INOLIĆ, E. (1998): Problems in the identification of lichen photobionts. Sauteria, 9: 373-380.

Gasulla, F., GuÉra, A. and Barreno, E. (2010): A simple and rapid method for isolating lichen photobionts. Symbiosis, 51: 175-179.

Gasulla, F., Jain, R., Barreno, E., Guéra, A., Balbuena, T. S., Thelen, J. J. and Oliver, M. J. (2013): The response of Asterochloris erici (Ahmadjian) Skaloud et Peksa to desiccation: a proteomic approach. Plant, Cell and Environment, doi: 10.1111/pce.12065.

GENTY, B., BRIANTAIS, J.-M. and BAKER, N. R. (1989): The relationship between quantum yield of photosynthetic electron transport and quenching of chlorophyll fluorescence. Biochimica et Biophysica Acta, 990: 87-92.

HáJeK, J., VÁczi, P., BARTÁK, M. and JAhNOvÁ, L. (2012): Interspecific differences in cryoresistance of lichen symbiotic algae of genus Trebouxia assessed by cell viability and chlorophyll fluorescence. Cryobiology, 64: 215-222.

He, Y., Zhang, Z. (2012): Diversity of organism in the Usnea longissima lichen. African Journal of Microbiology Research, 6: 4797-4804.

Kvíderová, J., Hájek, J., Elster, J. Barták, M., VÁczi, P. and Nedbalová, L. (2010): Photosynthetic microorganisms in cold environments. $38^{\text {th }}$ COSPAR Scientific Assembly. Held 18-15 July 2010, Bremen, Germany, p.7.

Lewis, L. A., McCourt, R. M. (2004): Green algae and the origin of land plants. American Journal of Botany, 91: 1535-1556.

Morlon, H., Fortin, C., Floriani, M., Adam, C., Garnier-Laplace, J. and Boudou, A. (2005): Toxicity of selenite in the unicellular green alga Chlamydomonas reinhardtii: Comparison between effects at the population and sub-cellular level. Aquatic Toxicology, 73: 65-78. 
Ocampo-Friedmann, R., Meyer, M. A., Chen, M. and Friedmann, E. I. (1998): Temperature response of Antarctic cryptoendolithic photosynthetic microorganisms. Polarforschung, 58: 121-124.

PeKSA, O., ŠKALOUD, P. (2011): Do photobionts influence the ecology of lichens? A case study of environmental preferences in symbiotic green alga Asterochloris (Trebouxiophyceae). Molecular Ecology, 20: 3936-3948.

Piovár, J., Stavrou, E., KADUKOVÁ, J., KimÁKovÁ, T. and BAČKor, M. (2011): Influence of longterm exposure to copper on the lichen photobiont Trebouxia erici and the free-living algae Scenedesmus quadricauda. Plant Growth Regulation, 63: 81-88.

SADOWsKy, A., OTт, S. (2012): Photosynthetic symbionts in Antarctic terrestrial ecosystems: the physiological response of lichen photobionts to drought and cold. Symbiosis, 58: 81-90.

Sankar, V., Daniel, D. K. and Krastanov, A. (2011): Carbon dioxide fixation by Chlorella minutissima batch cultures in a stirred tank bioreactor. Biotechnology \& Biotechnological Equipment, 25: 2468-2476.

Seaburg, K. G., Parker, B. C., Wharton, R. A. and Simmons, G. M. (1981): Temperaturegrowth responses of algal isolates from Antarctic oases. Journal of Phycology, 17: 353-360.

Showman, R. E. (1972): Photosyntetic response with respect to light in three strains of lichen algae. The Ohio Journal of Science, 72: 114-117.

Teoh, M.-L., Chu, W.-L., Marchand, H. and Phang, S.-M. (2004): Influence of culture temperature on the growth, biochemical composition and fatty acid profiles in six Antarctic microalgae. Journal of Applied Phycology, 16: 421-430.

VÁCZI, P., BARTÁK, M. (2006): Photosynthesis of lichen symbiotic alga Trebouxia erici as affected by irradiance and osmotic stress. Biologia Plantarum, 50: 257-264.

Vona, V., Rigano, V.D., Lobosco, O., Carfagna, S., Esposito, S. and Rigano, C. (2004): Temperature reponses of growth, photosynthesis, respiration, and NADH: Nitrate reductase in cryophilic and mesophilic algae. New Phytologist, 163: 325-331.

WienERS, P. C., Mudimu, O. and Bilger, W. (2012): Desiccation-induced non-radiative dissipation in isolated green lichen algae. Photosythesis Research, 113: 239-247. 